\title{
||||||||||||||||||||||||||||||||||||||||||||||||||||||||||||||||||||.
}

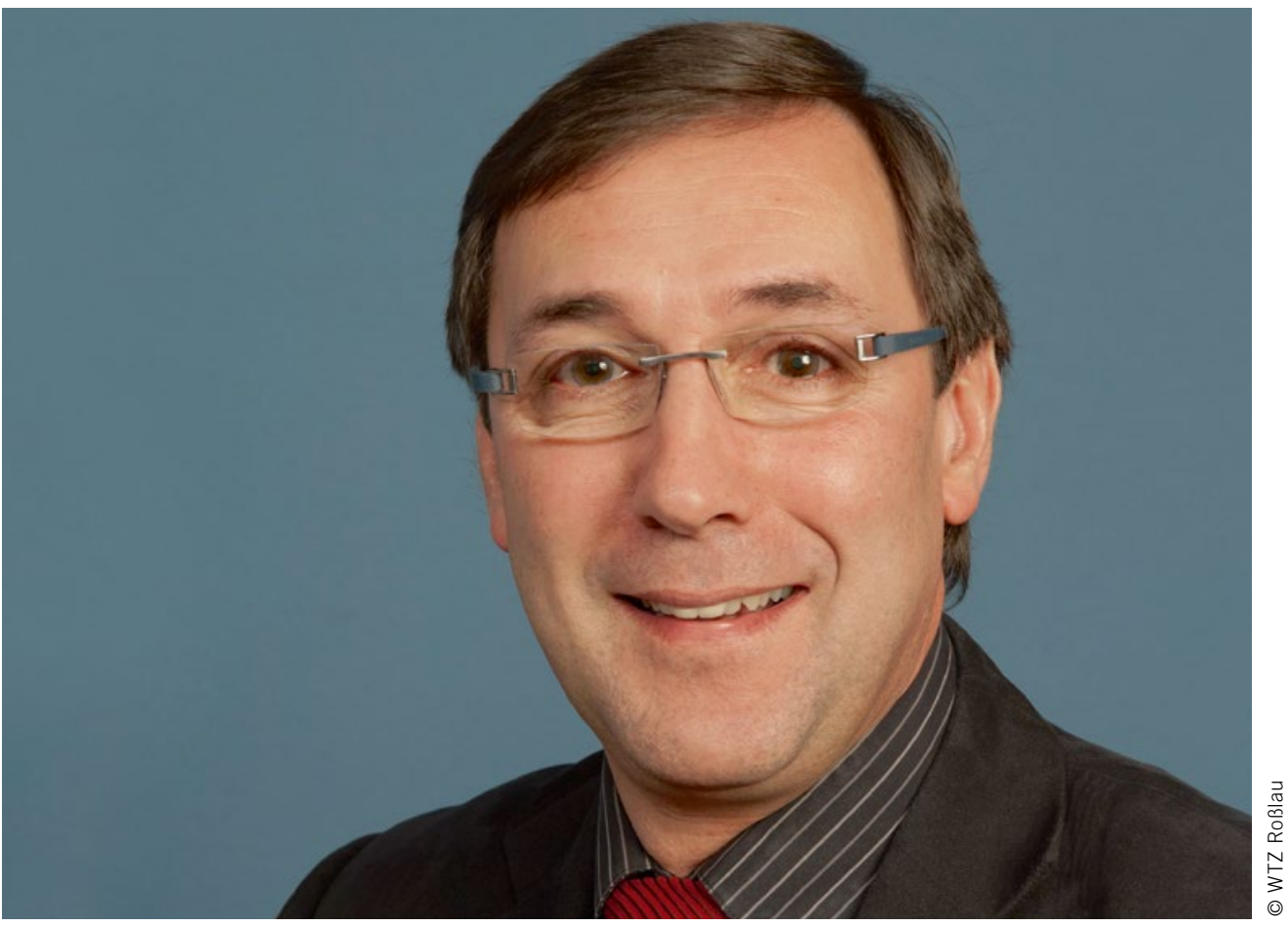

Dipl.-Ing. Günther Gern

CEO, WTZ Roßlau, Honorary Professor, Anhalt University of Applied Sciences (Germany)

\section{Gas Engines - The Outstanding Challenges}

With low $\mathrm{NO}_{\mathrm{x}}$ formation, high efficiencies and no-sulphur fuels with low carbon to hydrogen ratios, lean burn gas and dualfuel engines come close to the status of a cure-all technology for emissions.

A residual problem - in more than one sense - is, however, unburnt hydrocarbons, or methane slip. Since this is a greenhouse gas some 20 times more virulent than carbon dioxide, fuel escaping combustion has an effect out of proportion to the quantities involved.

With diesel engines recently matching gas engine efficiency, Otto-cycle researchers and developers cannot be happy with catalysts that burn escaped fuel unused. Hence R\&D is underway, pursuing both proven and promising approaches.

One is the reduction of dead volumes in the combustion chamber, such as the top-land gap between piston and cylinder, where methane can escape ignition. A solution already applied is longer strokes to reduce the gap as proportion of total combustion chamber volume. But this contradicts the standard practice of compensating power density by increasing bore diameters when gas engines are developed from platforms shared with diesels. Thus the search is concentrated on absolute reductions and in other regions of the chamber.

A very promising approach also associated with raising specific output is high pressure direct gas injection. Findings indicate that this promotes faster combustion, which both mitigates the expansion of the gas into zones where it can escape combustion and maximises heat release. Preconditions are both substantially higher gas inlet pressures to overcome charge compression close to top-dead-centre and higher energy ignition - whereby the latter is always desirable.

The attraction of high pressure gas injection is increased by its more direct controllability and because it forms a suitable counterpart to two-stage turbocharging, much as high pressure common rail does on diesels. The benefits of much higher charging pressures and efficiencies, notably as Miller Cycle enablers, are increased gas engine power density and load acceptance while reducing sensitivity to ambient conditions, and they have rapidly established themselves as stateof-the art. High pressure gas injection could help to further unlock the potential of two-stage turbocharging, but even on their own, higher turbocharger pressure ratios and efficiencies are already a key to raising gas engine specific output to the next level.

The current development goal is firing pressures of $300 \mathrm{bar}$ and BMEPs of 30 bar and higher, which will ensure the viability of next generation spark-ignited and dual-fuel engines as prime movers while their applications and usage expand rapidly. 